\title{
ESTUDO COMPARATIVO DE APRENDIZAGEM DE LÓGICA DE PROGRAMAÇÃO ENTRE ALUNOS DE ENSINO FUNDAMENTAL E MÉDIO
}

\author{
Andressa Hélen Gonçalves Ventura (andressa-hgv@ hotmail.com) \\ Bruno Victor Delmondes de Moura (brunodemoura_@hotmail.com) \\ Cecir Barbosa de Almeida Farias (cecir.almeida@gmail.com)
}

\section{Resumo}

Atualmente, com a globalização e o surgimento constante de novas tecnologias, se faz necessária a implantação de uma nova visão para o sistema educacional, buscando a adoção de novos métodos de ensino computacional para divulgar novos conteúdos entre os jovens. Um equívoco comum na divulgação de conhecimentos sobre novas tecnologias, é apresentar conteúdos gerais, sem levar em consideração o conhecimento prévio dos alunos e a faixa etária dos mesmos, acarretando em baixo aprendizado e desistência durante o período de aulas. Com isso, o presente estudo objetiva a utilização de uma abordagem comparativa baseada em dados reais, coletados em duas escolas da rede pública de ensino de uma cidade do interior da Paraíba, com alunos do ensino fundamental II e do ensino médio, a fim de proporcionar a Inclusão Digital através da Lógica e Programação com o uso da plataforma MIT App Inventor. Com o auxílio de um Questionário on-line sobre Lógica e Pensamento Computacional foi proposto obter o nível de conhecimento prévio dos alunos e elaborar material didático adequado para cada faixa etária de acordo com a nível de conhecimento existente.

Palavras-chaves: Programação para celular, Linguagem de Blocos, Aplicativos

\section{Introdução}

O uso de tecnologias se faz presente no cotidiano de diversas pessoas, principalmente para grande maioria dos jovens que as experimentam através de dispositivos móveis, como telefones e tablets. Nesse contexto, são discutidas formas de usufruir dessas ferramentas no âmbito escolar para que essas tecnologias sejam utilizadas a fim de agregar valor ao conhecimento e influenciar o aluno a utilizar essas ferramentas para melhor aprendizagem. De acordo com Parcianello, Konzen (2016), a tecnologia pode vir a ser uma extensão da sala de aula na busca por mais conhecimento, viabilizando novos modos de aprendizagem e 
ensino. Logo, é de suma importância para o educador a utilização dessa ferramenta para desenvolvimento e reforço do aprendizado.

Para incentivar o pensamento computacional e influenciar a divulgação de conhecimentos na área de lógica de programação para os alunos, é necessário buscar ferramentas que possam apoiar o educador a transmitir novos conhecimentos. Nesse contexto, Gomes e Melo (2013) apresentam uma abordagem de uso do App Inventor para propiciar experiências mais atrativas de ensino e aprendizagem. O App Inventor (MIT, 2012) é uma plataforma orientada para produção de aplicações para a plataforma Google Android, feita através de programação em blocos, ou seja, produzida a partir da junção de blocos lógicos pré-definidos contendo comandos de programação.

Este artigo apresenta um comparativo de conhecimentos de alunos do ensino fundamental II ( $9^{\circ}$ anos) e ensino médio ( $1^{\circ}, 2^{\circ}$ e $3^{\circ}$ Anos), através da análise de questionários aplicados sobre lógica e programação em blocos, com os futuros alunos do Projeto "Inclusão Digital através da Lógica e Programação para Alunos do Ensino Fundamental II e Médio na cidade de Sumé, PB, com o uso da plataforma App Inventor".

\section{Referencial Teórico}

\subsection{Importância do desenvolvimento da lógica e do pensamento computacional}

De acordo com Forbellone (2005), a lógica pode ser definida como sendo a arte de bem pensar e estuda a correção do raciocínio. Tudo o que envolve a computação tem como origem a construção lógica dos componentes, softwares e conexões. Para Rocha, et al. (2010), a lógica de programação é um requisito fundamental nos cursos de computação, e é um instrumento importante na estruturação do raciocínio lógico e formulação de algoritmos corretos.

O processo de ensino de lógica de programação é permeado por diversos desafios que englobam desde as dificuldades dos alunos na compreensão do problema proposto e em questões relativas à abstração, até mesmo falta de consenso no que diz respeito aos requisitos prévios necessários para um desempenho satisfatório na aprendizagem (Falkembach et al. 2003).

Rocha (2010) destaca que é importante compreender o ritmo de aprendizagem de cada indivíduo, observado o tempo de assimilação do entendimento dos conteúdos por cada aluno. Este fator pode acarretar em dificuldades na aprendizagem por parte dos alunos e ocasionar 
em um desinteresse pelo conteúdo da disciplina e motivar a desistências dos cursos.

Nesse sentido, de acordo com Barcelos et al. (2009), o ensino de algoritmos e programação nas instituições tornou-se um frequente objeto de estudos, na intenção da melhoria do desempenho do corpo discente, pois é sabido que estes conteúdos possuem extrema importância tanto para professores quanto para a trajetória acadêmica dos estudantes em diversas áreas, como matemática, física e informática.

\subsection{Ensino de lógica de programação nas escolas}

Com a globalização e o surgimento de novas tecnologias, faz-se necessária a implantação de novos métodos no ensino computacional. Nesse contexto, tem-se inúmeros estudantes dos ensinos médio e fundamental que, independente de classe socioeconômica, procuram conhecimentos a fim de tornarem-se capacitados a trabalhar com diferentes instrumentos produzidos pela computação.

O pensamento computacional e práticas de programação no contexto escolar trazem inúmeros benefícios para o desenvolvimento do aluno. Conforme relata Scaico et al. (2013), este tipo de educação permite o desenvolvimento de diversas capacidades que contribuem para melhorar o raciocínio lógico dos estudantes. Outra razão para inserir o ensino de programação nas escolas seria que tal proximidade pode contribuir para mostrar aos alunos novas possibilidades de uso das tecnologias que habitualmente manuseiam. Ademais, o pensamento computacional e a prática programacional apoiam o desenvolvimento de habilidades de abstração, raciocínio lógico, decomposição e resolução de problemas.

Contudo, são encontados alguns obstáculos em sala de aula que dificultam aplicação de algumas dessas ferramentas de ensino. De acordo com Saeli (2011), o cenário de uma sala de aula é um ambiente complexo, onde muitos processos e ações estão acontecendo simultaneamente e que é influenciado pelo estilo de aprendizagem dos alunos. Neste sentido, são identificadas cinco dificuldades frequentes que são capazer de provocar distúrbios na ação de ensinar e de aprender programação, onde os mesmos estão relacionados tanto a aspectos motivacionais quanto técnicos dos estudantes, se referindo a:

- Entender a utilidade da programação e os seus benefícios;

- Compreender as propriedades gerais de uma máquina (um computador, no caso) que o aluno está aprendendo a controlar;

- Aprender uma nova notação, que pode provocar problemas relacionados aos aspectos de 
sintaxe e semântica das linguagens de programação;

- Entender o uso correto das estruturas de programação;

- Atingir proficiência nas habilidades necessárias à implementação, sejam elas especificar, codificar, depurar e testar o código.

Segundo Kelleher and Pausch (2005), a questão da sintaxe é a maior dificuldade encontrada pelos iniciantes em programação, pois nem todas as linguagens são claras. Simplificar a sintaxe, fazendo com que fiquem mais próximas da linguagem natural, ajudaria muito no aprendizado mais rápido da programação. Sabendo disto, são várias as iniciativas de ambientes de programação que tenham um intuito educativo, dentre elas é possível destacar as linguagens baseadas em blocos.

Sabendo que os atuais alunos das turmas de ensino fundamental e médio possuem acesso a smartphones, foi perceptível a oportunidade de utilizar uma ferramenta que fornecesse um ambiente para criação de aplicativos para estes dispositivos, que fosse capaz de estimular o interesse dos estudantes em aprender linguagem de programação. Neste sentido, é explorado o uso do ambiente para desenvolvimento MIT App Inventor (MIT, 2012) que foi criado no intuito de facilitar o aprendizado de programação e criação de aplicativos Android.

\subsection{Ferramenta App Inventor}

O MIT App Inventor é um ambiente de programação visual intuitivo que permite a todos - até crianças - criar aplicativos totalmente funcionais para smartphones e tablets. Os novos usuários do MIT App Inventor podem ter um primeiro aplicativo simples em funcionamento em menos de 30 minutos. Além disso, nossa ferramenta baseada em blocos facilita a criação de aplicativos complexos e de alto impacto em um tempo significativamente menor que os ambientes de programação tradicionais. O projeto MIT App Inventor procura democratizar o desenvolvimento de software, capacitando todas as pessoas, especialmente os jovens, a passar do consumo de tecnologia para a criação de tecnologia (MIT, 2012).

Segundo Abelson (2009), esta linguagem foi projetada com o objetivo de tornar o processo de ensino-aprendizagem dos fundamentos de computação mais atraente, visando provocar mudanças positivas nas experiências, “[...] tendo como alvo as pessoas e suas interações com os outros e com o mundo ao seu redor, em detrimento de cenários que incluem estudantes desmotivados, sentados em laboratórios escrevendo programas que ninguém jamais usará".

O uso da ferramenta para criação de aplicativos é bem intuitivo: para iniciar, é necessário 
abrir no navegador no site appinventor.mit.edu e selecionar a opção de "criação de aplicativos". O mesmo exige que se faça login com uma conta no Google para abrir o ambiente de criação.

O ambiente possui diversas ferramentas para a criação do aplicativo para celular. Este ambiente é composto por duas janelas principais: Editor de Ecrãs e Blocos. A janela de designer é composta por algumas abas principais, sendo elas: paleta, visualizador, componentes e propriedades, ferramentas responsáveis pela interface do aplicativo (Figura 1). A janela de edição de blocos é composta pelas abas de blocos e visualizador, responsáveis pela programação do app que será sendo desenvolvido (Figura 2).

Figura 1 - Editor de Ecrãs

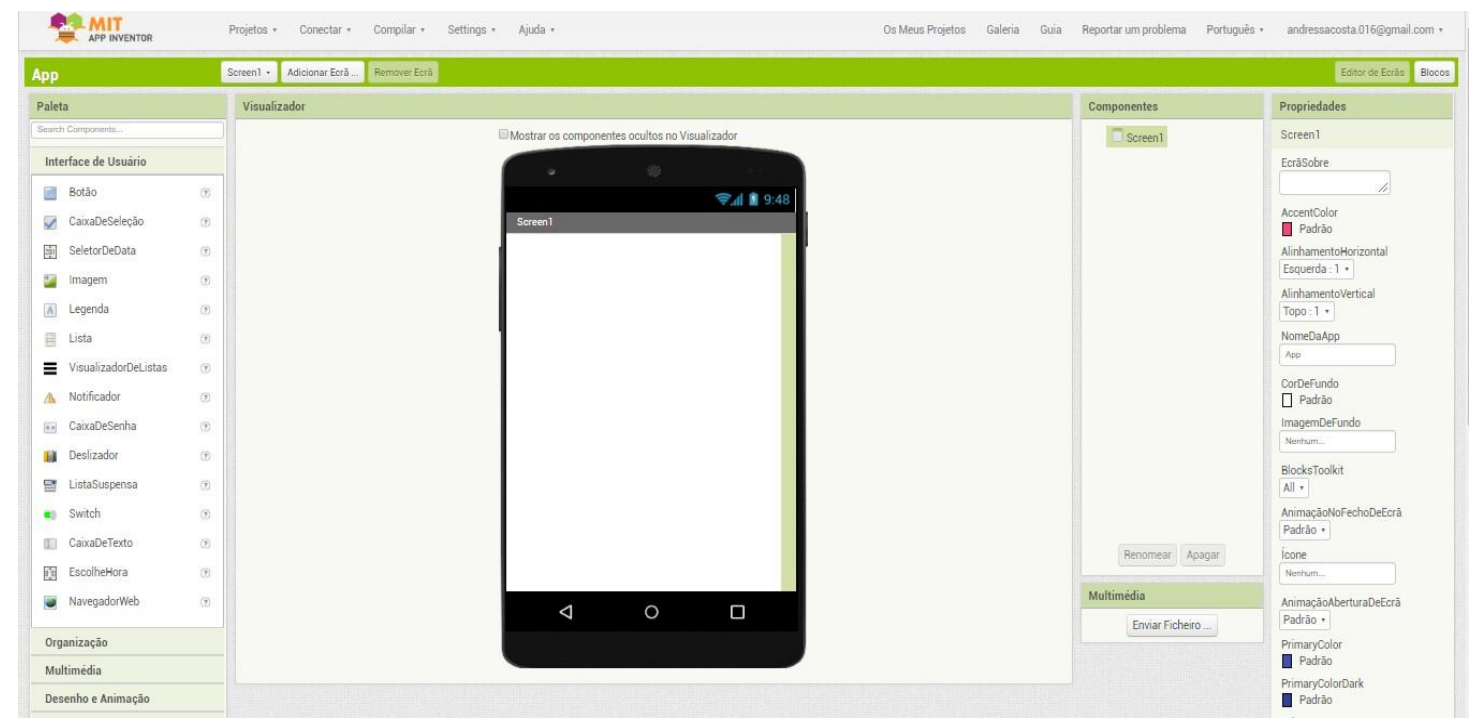

Fonte: Autoria própria, 2019 
Figura 2 - Blocos

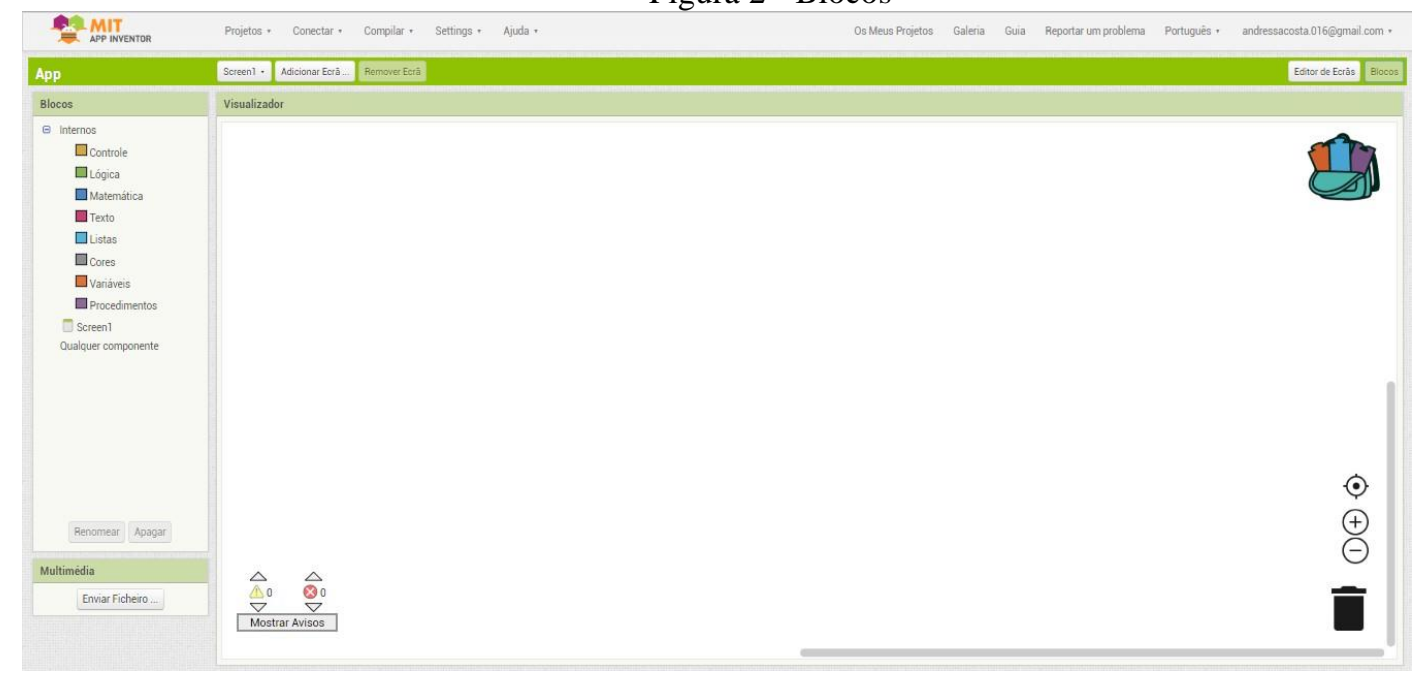

Fonte: Autoria própria, 2019

\section{Metodologia}

Este estudo, em relação à abordagem da pesquisa, é classificado como uma abordagem qualitativa, de natureza aplicada, pois se busca analisar de forma subjetiva os conhecimentos prévios dos alunos do ensino médio e do ensino fundamental II a partir da aplicação de questionários dinâmicos sobre lógica de programação no primeiro dia de aula, tendo como ferramenta base o App Inventor.

De acordo com Ludke e André (2013) a pesquisa qualitativa se caracteriza por envolver a obtenção de dados descritivos, que são obtidos no contato direto do pesquisador com a situação estudada e enfatiza mais o processo do que o produto e se preocupa em retratar a perspectiva dos participantes.

O objetivo principal do projeto que geriu os dados que serão abordados neste artigo é proporcionar Inclusão Digital através da Lógica e Programação com da ferramenta App Inventor aos alunos das escolas selecionadas. Para tanto, fez-se necessário a aplicação de questionários iniciais na busca de obter dados sobre o nível de conhecimento do grupo amostral em lógica e programação.

O questionário aplicado é bastante dinâmico, com ilustração de figuras e pede ao final uma auto-avaliação do desempenho do aluno. O mesmo é composto por vinte e oito questões de múltiplas escolhas (com 5 alternativas), e foi aplicado para vinte e três alunos da turma do ensino médio e alunos da turma do ensino fundamental. 
O questionário aplicado foi desenvolvido por Ramon Goonçalez, disponível em https://docs.google.com/forms/d/e/lFAIpQLSeQrpfVWLDAD-

$3 O j K 5 I 23 S D C p 7 z x 9 G n f D G I Y C b b U g 6 \operatorname{Pr} 4 f z T w / v i e w f o r m$. A Figura 3 expõe uma das questões do questionário.

Figura 3 - Questão 2 do questionário de Pensamento Computacional

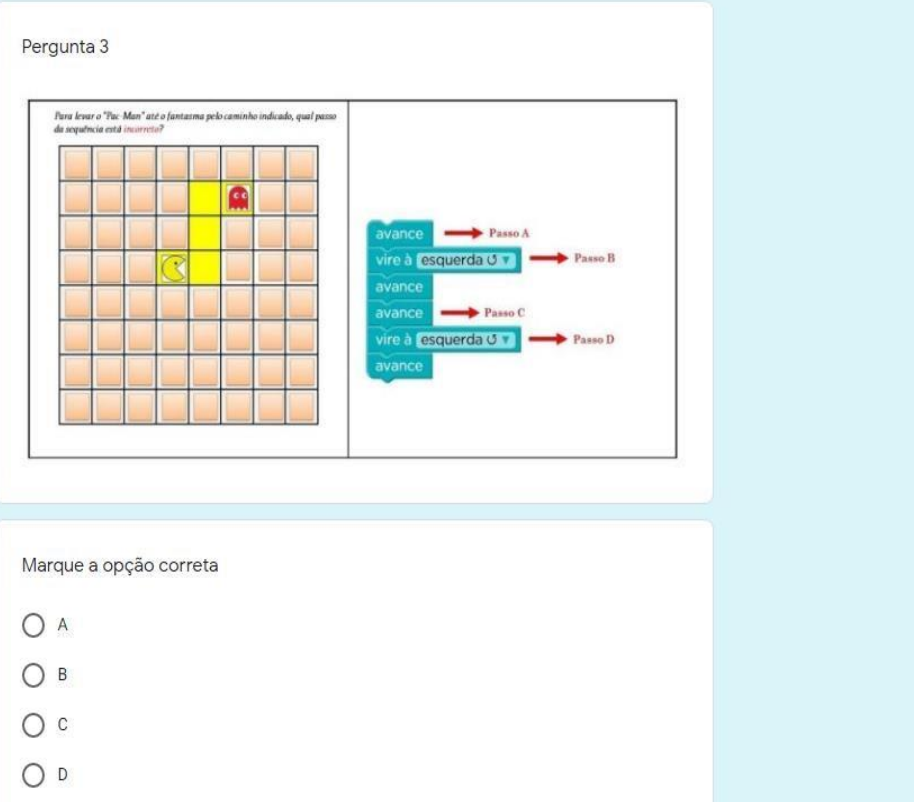

Fonte: (Goonçalez, 2019)

\section{Resultados e discussão}

\subsection{Coleta de dados}

A partir dos dados obtidos através da aplicação do questionário, foi possível analisar a quantidade de erros e acertos de cada aluno de ambas as turmas. Desse modo, as Tabelas $1 \mathrm{e}$ 2 apresentam, de forma quantitativa, erros e acertos obtidos a partir das resolução dos questionários pelos alunos do ensino médio e dos alunos do ensino fundamental II. 
Tabela 1 - Dados do questionário aplicado ao ensino médio

\begin{tabular}{|c|c|c|c|c|c|}
\hline \multicolumn{3}{|c|}{ Dados descritivos } & \multicolumn{3}{|c|}{ Dados Percentuais } \\
\hline Questão & $\mathrm{N}^{\circ}$ de acertos & $\begin{array}{l}\mathrm{N}^{\circ} \mathrm{de} \\
\text { erros }\end{array}$ & Total de respostas & Percentual de acerto & $\begin{array}{c}\text { Percentual de } \\
\text { erros }\end{array}$ \\
\hline 1 & 19 & 4 & 23 & 82,609 & 17,391 \\
\hline 2 & 12 & 11 & 23 & 52,174 & 47,826 \\
\hline 3 & 8 & 15 & 23 & 34,783 & 65,217 \\
\hline 4 & 6 & 17 & 23 & 26,087 & 73,913 \\
\hline 5 & 11 & 12 & 23 & 47,826 & 52,174 \\
\hline 6 & 13 & 10 & 23 & 56,522 & 43,478 \\
\hline 7 & 4 & 19 & 23 & 17,391 & 82,609 \\
\hline 8 & 3 & 20 & 23 & 13,043 & 86,957 \\
\hline 9 & 12 & 11 & 23 & 52,174 & 47,826 \\
\hline 10 & 14 & 9 & 23 & 60,870 & 39,130 \\
\hline 11 & 5 & 18 & 23 & 21,739 & 78,261 \\
\hline 12 & 3 & 20 & 23 & 13,043 & 86,957 \\
\hline 13 & 10 & 13 & 23 & 43,478 & 56,522 \\
\hline 14 & 6 & 17 & 23 & 26,087 & 73,913 \\
\hline 15 & 6 & 17 & 23 & 26,087 & 73,913 \\
\hline 16 & 7 & 16 & 23 & 30,435 & 69,565 \\
\hline 17 & 3 & 20 & 23 & 13,043 & 86,957 \\
\hline 18 & 9 & 14 & 23 & 39,130 & 60,870 \\
\hline 19 & 10 & 13 & 23 & 43,478 & 56,522 \\
\hline 20 & 11 & 12 & 23 & 47,826 & 52,174 \\
\hline 21 & 3 & 20 & 23 & 13,043 & 86,957 \\
\hline 22 & 5 & 18 & 23 & 21,739 & 78,261 \\
\hline 23 & 7 & 16 & 23 & 30,435 & 69,565 \\
\hline 24 & 12 & 11 & 23 & 52,174 & 47,826 \\
\hline 25 & 4 & 19 & 23 & 17,391 & 82,609 \\
\hline 26 & 10 & 13 & 23 & 43,478 & 56,522 \\
\hline 27 & 11 & 12 & 23 & 47,826 & 52,174 \\
\hline 28 & 8 & 15 & 23 & 34,783 & 65,217 \\
\hline TOTAL & 232 & 412 & & & \\
\hline
\end{tabular}

Fonte: Autoria própria, 2019

A partir dos dados acima, é possível demostrar no Gráfico 1 a relação da média global de acertos e erros dos alunos e a relação do número de acertos e erros por questão de cada aluno de acordo com o gráfico 2 . 
Gráfico 1 - Média global de acertos e erros dos alunos do Ensino Médio

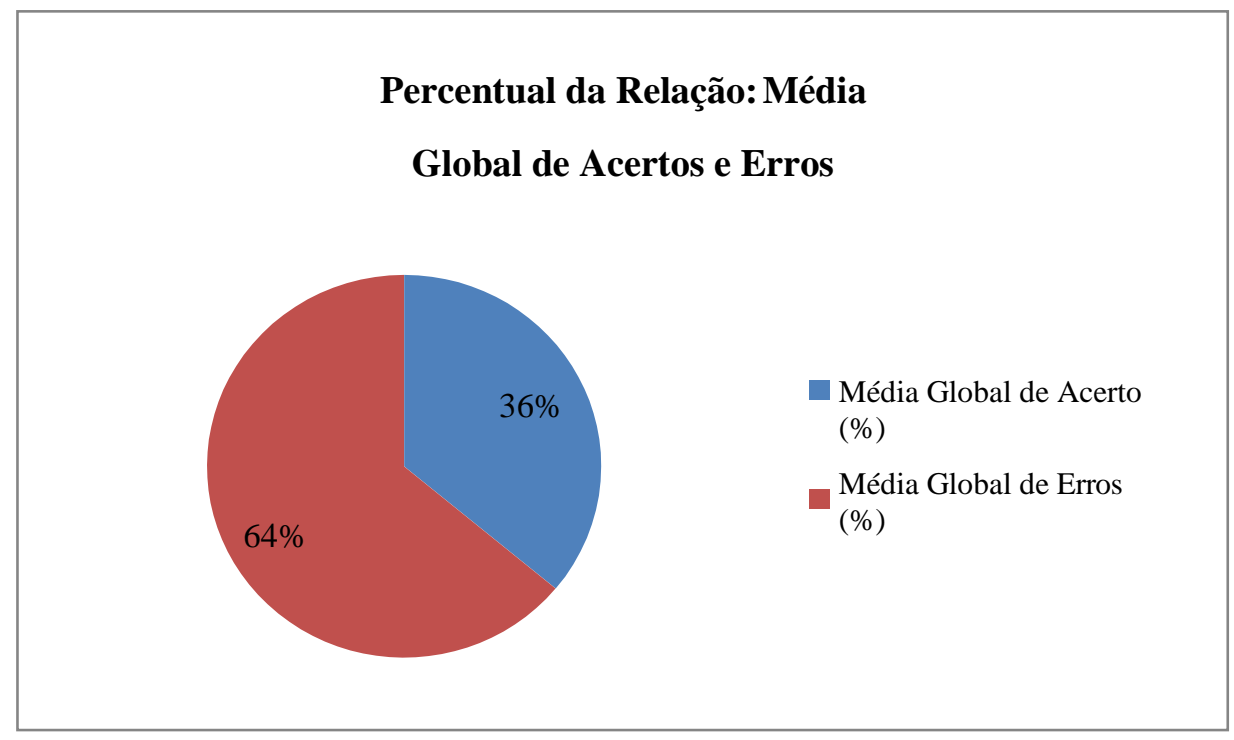

Fonte: Autoria própria, 2019

Gráfico 2 - Relação do número de acertos e erros por questão

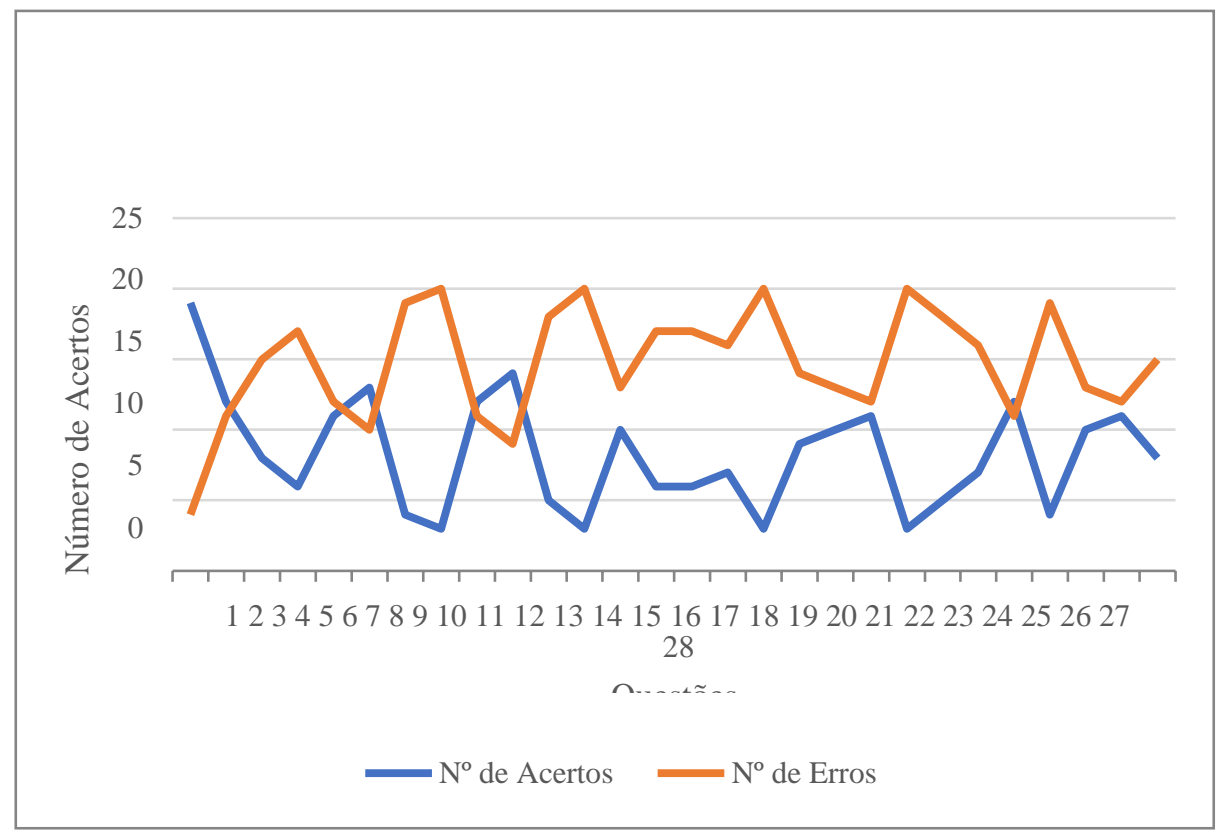

Fonte: Autoria própria, 2019 
Tabela 2 - Dados do questionário aplicado ao ensino Fundamental II

\begin{tabular}{|c|c|c|c|c|c|}
\hline \multicolumn{3}{|c|}{ Dados descritivos } & \multicolumn{3}{|c|}{ Dados Percentuais } \\
\hline Questão & $\mathrm{N}^{\circ}$ de acertos & $\begin{array}{l}\mathrm{N}^{\circ} \mathrm{de} \\
\text { erros }\end{array}$ & Total de respostas & Percentual de acerto & $\begin{array}{c}\text { Percentual } \\
\text { de erros }\end{array}$ \\
\hline 1 & 21 & 0 & 21 & 100,00 & 0,000 \\
\hline 2 & 21 & 0 & 21 & 100,00 & 0,000 \\
\hline 3 & 13 & 8 & 21 & 61,905 & 38,095 \\
\hline 4 & 19 & 1 & 20 & 95,000 & 5,000 \\
\hline 5 & 20 & 1 & 21 & 95,238 & 4,762 \\
\hline 6 & 18 & 3 & 21 & 85,714 & 14,286 \\
\hline 7 & 21 & 0 & 21 & 100,000 & 0,000 \\
\hline 8 & 11 & 10 & 21 & 52,381 & 47,619 \\
\hline 9 & 20 & 1 & 21 & 95,238 & 4,762 \\
\hline 10 & 21 & 0 & 21 & 100,000 & 0,000 \\
\hline 11 & 21 & 0 & 21 & 100,000 & 0,000 \\
\hline 12 & 17 & 4 & 21 & 80,952 & 19,048 \\
\hline 13 & 3 & 17 & 20 & 15,000 & 85,000 \\
\hline 14 & 0 & 21 & 21 & 0,000 & 100,000 \\
\hline 15 & 20 & 3 & 23 & 86,957 & 13,043 \\
\hline 16 & 5 & 18 & 23 & 21,739 & 78,261 \\
\hline 17 & 2 & 21 & 23 & 8,696 & 91,304 \\
\hline 18 & 9 & 14 & 23 & 39,130 & 60,870 \\
\hline 19 & 22 & 3 & 23 & 88,000 & 12,000 \\
\hline 20 & 5 & 18 & 23 & 21,739 & 78,261 \\
\hline 21 & 8 & 15 & 23 & 34,783 & 86,957 \\
\hline 22 & 3 & 20 & 23 & 13,043 & 86,976 \\
\hline 23 & 12 & 11 & 23 & 52,174 & 47,826 \\
\hline 24 & 0 & 23 & 23 & 0,000 & 100,000 \\
\hline 25 & 0 & 23 & 23 & 0,000 & 100,000 \\
\hline 26 & 4 & 19 & 23 & 17,391 & 82,609 \\
\hline 27 & 17 & 5 & 23 & 77,273 & 22,727 \\
\hline 28 & 18 & 5 & 23 & 78,261 & 21,739 \\
\hline TOTAL & 351 & 264 & & & \\
\hline
\end{tabular}

Fonte: Autoria própria, 2019

O Gráfico 3, obtido a partir dos dados apresentados na Tabela 2, apresenta a relação da média global de acertos e erros dos alunos do ensino fundamental II e a relação do número de acertos e erros por questão de cada aluno, de acordo com o Gráfico 4. 
Gráfico 3 - Média global de erros e acertos dos alunos do Ensino Fundamental II

Percentual da Relação: Média Global de Erros e Acertos

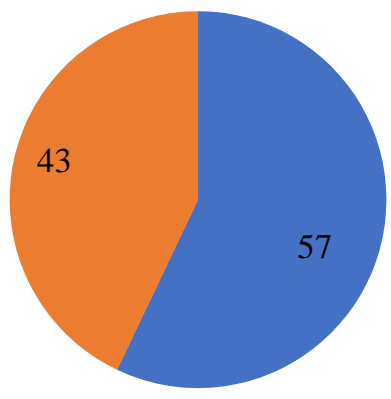

- Média Global de Acertos Média Global de Erros

Fonte: Autoria própria, 2019

Gráfico 4 - Relação do número de acertos e erros por questão

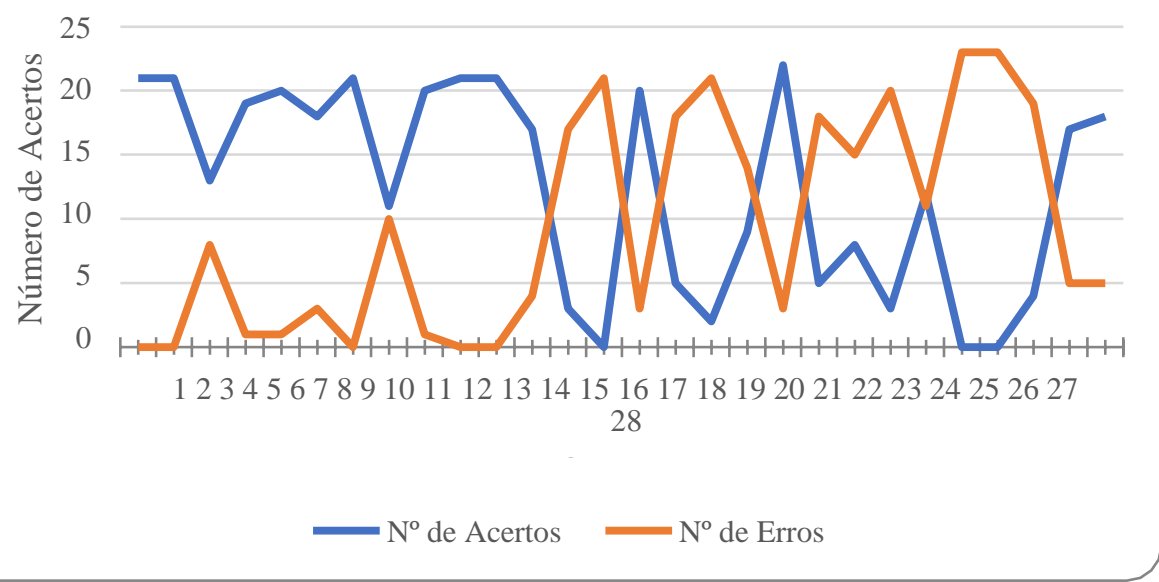

Fonte: Autoria própria 


\subsection{Discussão e análise dos dados do questionário}

\subsubsection{Dados do ensino médio}

A seguir serão discutidos sobre os dados obtidos a partir das respostas dos alunos do ensino médio, referente a cinco questões do questionário aplicado:

Questão 1: "Qual sequência leva o "Pac Man” até o fantasma pelo caminho indicado?"

Os dados coletados referentes à primeira questão demonstram que de um total de vinte e três participantes, dezenove $(82,60 \%)$ alunos responderam corretamente e apenas cinco $(17,39 \%)$ de forma incorreta.

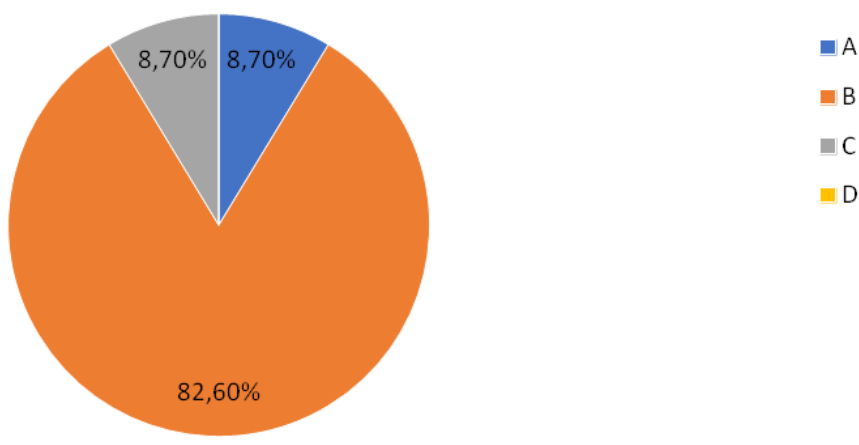

Questão 2: "Qual comando está faltando na sequência para levar o "Pac Man” até o fantasma pelo caminho indicado?"

Observou-se que, na segunda questão, doze $(52,17 \%)$ alunos assinaram a resposta correta e onze $(47,82 \%)$ alguma das alternativas incorretas.

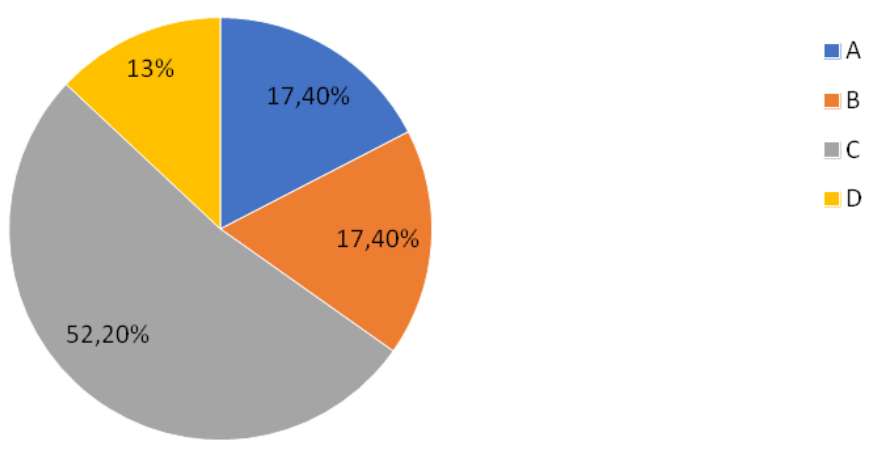


Questão 3: "Para levar o "Pac Man" até o fantasma pelo caminho indicado, qual passo da sequência está incorreto?”

$\mathrm{Na}$ terceira questão, houve um decréscimo no número de acertos, apenas oito $(34,78 \%)$ responderam corretamente, enquanto os outros quinze $(65,21 \%)$ estudantes erraram ao responder.

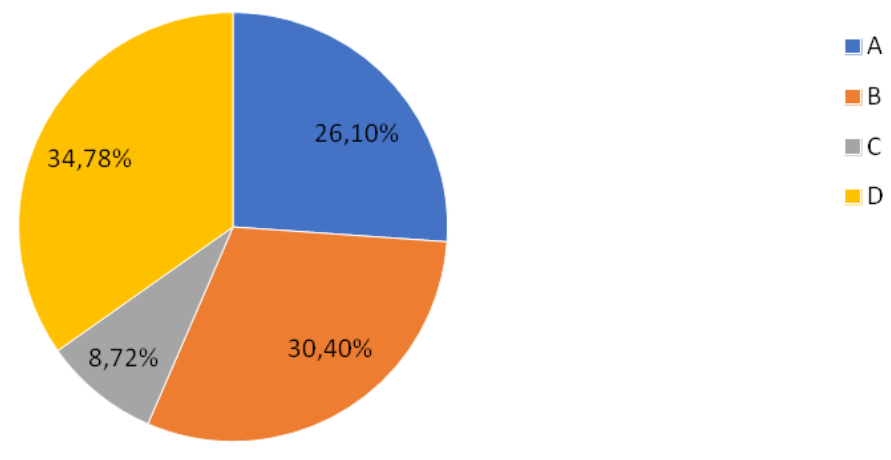

Questão 4: "Qual sequência o artista deve seguir para desenhar o quadro abaixo? Cada um dos lados mede 100 pixels.”

Os dados da quarta pergunta demonstram um decréscimo ainda maior no número de respostas corretas, tendo apenas seis $(26,08 \%)$ alunos respondido corretamente e os outros dezessete $(73,91 \%)$ de forma incorreta.

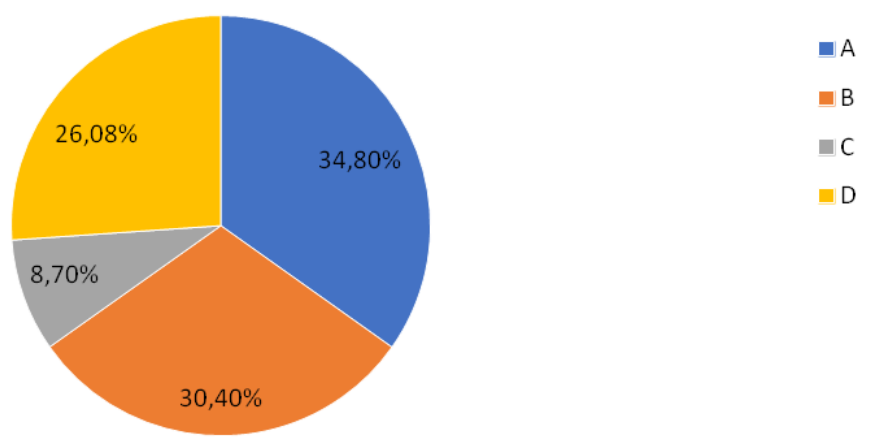

Questão 7: "Para que o artista desenhe uma vez o seguinte retângulo (50 pixels de largura e 100 pixels de altura), qual passo de sequência está incorreto?" 
Identificou-se uma relevante baixa na quantidade de acertos, tendo apenas quatro $(17,39 \%)$ alunos respondido corretamente e dezenove $(82,60 \%)$ assinalado alguma das alternativas incorretas.

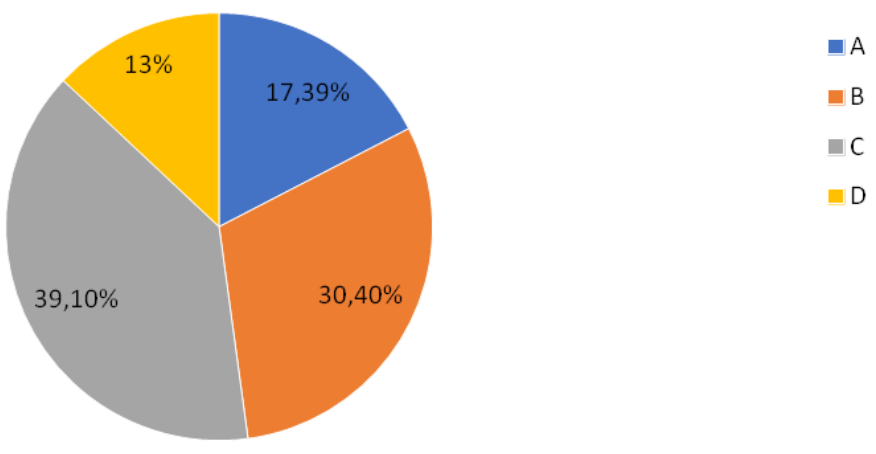

De acordo com o percentual de erros e acertos das questões respondidas pelas turmas do ensino médio, é possível analisar que os mesmos não tiveram um bom desempenho geral, gerando maior porcentagem de respostas erradas, uma porcentagem de 64\% (maioria dos alunos) e apenas $36 \%$ de acertos. 


\subsubsection{Dados do ensino fundamental II}

A seguir, serão discutidos sobre os dados das respostas obtidas com vinte e três alunos do 9o. ano do ensino fundamental II referente a cinco questões do questionário aplicado. Sabendo que entre a primeira pergunta e a décima quarta houve a ausência de alguns alunos que não quiseram responder, os cálculos percentuais de erros e acertos fora feito com base nos alunos que responderam (21).

Questão 1: "Qual sequência leva o "Pac Man” até o fantasma pelo caminho indicado?" Os dados coletados referentes à primeira questão demonstram que, de um total de vinte e três participantes, vinte e um participaram, obtendo vinte e um (100\%) alunos que responderam corretamente e zero $(0,0 \%)$ de forma incorreta.

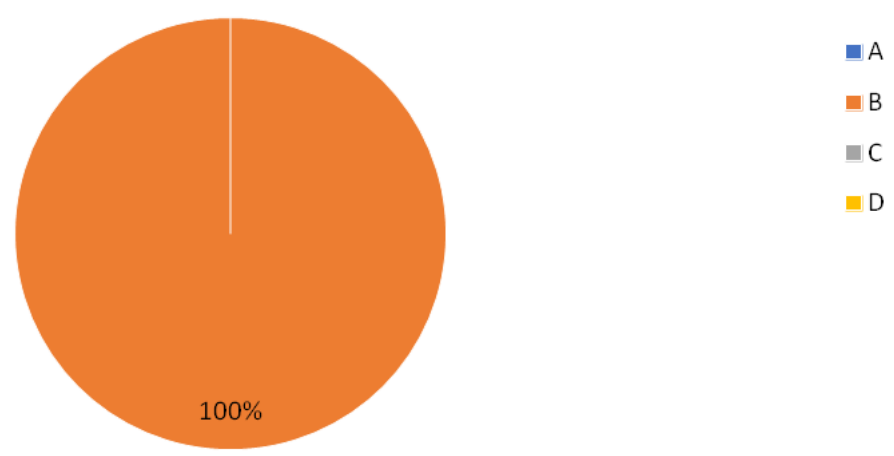

Questão 3: "Para levar o "Pac Man" até o fantasma pelo caminho indicado, qual passo da sequência está incorreto?"

$\mathrm{Na}$ terceira questão houve um decréscimo no número de acertos, apenas treze $(61,905 \%)$ responderam corretamente, enquanto os outros oitos $(38,095 \%)$ estudantes erraram ao responder. 


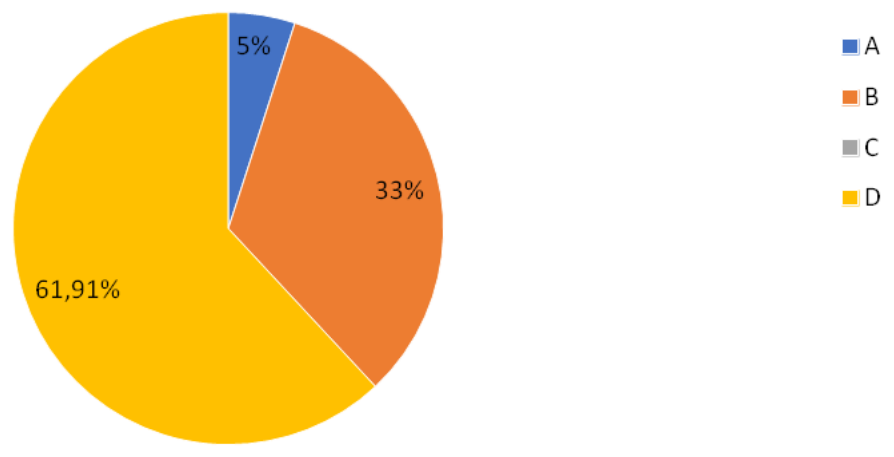

Questão 4: "Qual sequência o artista deve seguir para desenhar o quadro abaixo? Cada um dos lados mede 100 pixels."

Os dados da quarta pergunta demonstram um acréscimo no número de respostas corretas, tendo dezenove (95\%) alunos respondido corretamente e apenas um (5\%) de forma incorreta.

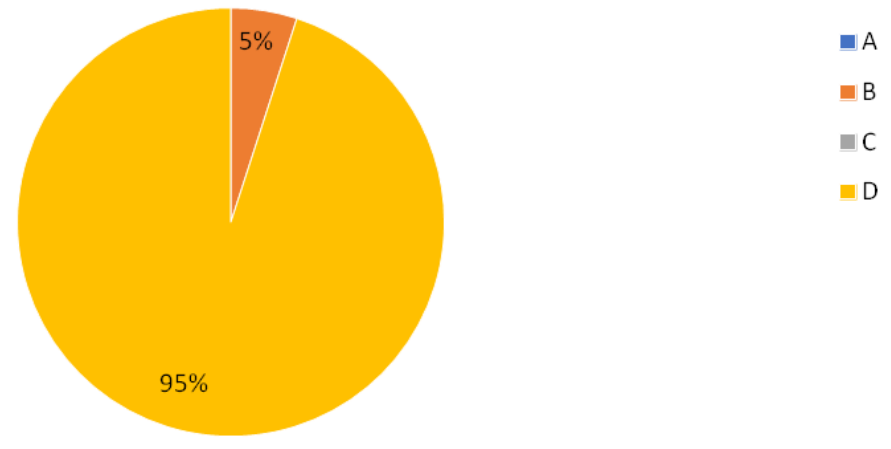

Questão 5: "Qual sequência leva o "Pac Man” até o fantasma pelo caminho indicado?" A quinta questão mostra que vinte $(95,238 \%)$ estudantes acertaram enquanto apenas só um $(4,762 \%)$ errou ao responder.

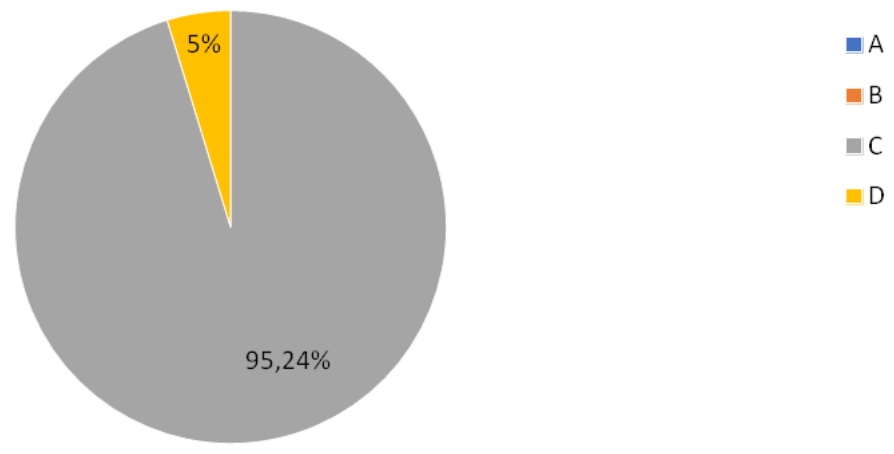


Questão 12: "Qual sequência o artista deve seguir para desenhar a escada que leva até a flor? Cada degrau sobre 30 pixels."

Apresenta-se também como uma das questões com alto índice de acertos, isto é, dezessete $(80,952 \%)$.

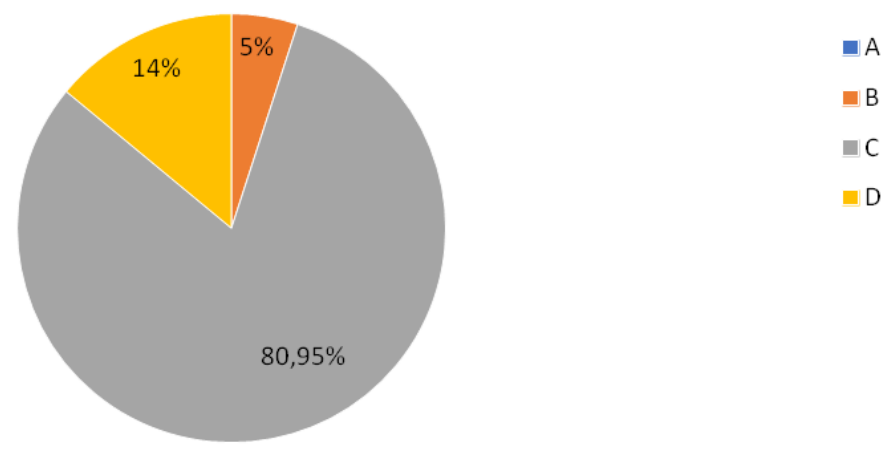

De acordo com o percentual de erros e acertos da turma do ensino fundamental II é possível observar que os alunos obtiveram um resultado positivo pois garantiram uma porcentagem maior de acertos $(57 \%)$ e porcentagem de erros de $43 \%$.

\section{Considerações finais}

Este artigo possui como ideia principal apresentar um estudo realizado no projeto de extensão da UFCG - Universidade Federal de Campina Grande, campus CDSA - Centro de Desenvolvimento Sustentável do Semiárido, vinculado ao PROBEX - Programa de Bolsas de Extensão da UFCG a fim de se obter o nível de conhecimento dos alunos antes da realização do curso de Programação para Celular com a ferramenta MIT App Inventor. Para isto, foi aplicado um questionário on-line (Gonçales, 2015) com questões embasadas nas áreas da lógica de programação e pensamento computacional, justamente para que se pudesse obter dados sobre o conhecimento já presente nos alunos e também suas deficiências, o que poderia ser trabalho nas aulas do projeto em questão. Foi aplicado o mesmo questionário para duas turmas, uma com alunos do ensino médio e outra com alunos do ensino fundamental II de escolas da rede pública de ensino.Neste sentido, foi possível notar que os alunos do ensino fundamental II obtiveram uma quantidade maior de acertos (57\%) comparando com os alunos do ensino médio (36\%), comprovando a teoria de que quanto mais jovem, mais fácil de obter entendimento e aprendizagem sobre a lógica de programação. Com base nestes dados, a 
equipe do projeto de extensão (professores e alunos das áreas de computação e engenharia de produção) elaborou o material do curso de Programação e Lógica, adequando-o às diferentes faixas etárias, para que assim, todos os alunos da rede pública pudessem aprender a programar para celular com a ferramenta MIT App Inventor. O projeto obteve em seu primeiro ano uma boa quantidade de aplicativos criados para celular em diversas áreas, tais como jogos e aplicativos para o uso diário dos alunos, os quais, em sua maioria (87\%), permaneceram nas aulas até o final do ano e poderão dar continuidade no desenvolvimento de suas habilidades, com base nos conhecimentos aprendidos.

\section{BIBLIOGRAFIA}

ABELSON, H. App Inventor for Android. 2009. Disponível em:

<http://googleresearch.blogspot.com/2009/07/app-inventor-for-android.html >Acesso em: 19 de março de 2019.

BARCELOS, R. J. S.; TAROUCO, L.; BERCH, M. O Uso do Mobile Learning no Ensino de Algoritmos. Renote- Revista Novas Tecnologias na Educação, PortoAlegre-RS, Brasil. v. 7, n. 2, p. 237-337, dez. 2009. FALKEMBACH, G. A. M., AMORETTI, M. S. M., TAROUCO, L. R., VIERO, F. (2003). Aprendizagem de Algoritmos: Uso da Estratégia Ascendente de Resolução de Problemas. $8^{\circ}$ Taller Internacional de Software Educativo. Santiago: Chile.

FORBEllONE, A.L. V.; EBERSPACHER, H. F. Lógica de Programação. São Paulo, ed. Pearson Prentice Hal, 2005.

GOMES, T. C. S; MELO, J. C. B. . O Pensamento Computacional no Ensino Médio: Uma Abordagem Blended Learning. Anais do XXXIII Congresso da Sociedade Brasileira da Computação. Maceió. 2013 GOONÇALEZ, Ramon. Questionário do Pensamento Computaconal. 2015. Disponível em: <https://docs.google.com/forms/d/1sgJnuXUjvOARs2y8EJLRWoIMuOXIHyo4-luqzrpOpQQ/edit> Acessado em: 19 de abril de 2019.

KELLHER, C. and PAUSCH, R. (2005). Lowering the barriers to programming: A taxonomy of programming environments and languages for novice programmers. ACM Computing Surveys (CSUR), 37(2):83-137.

LÜDKE, Menga; ANDRÉ, M. E.D.A. Pesquisa em Educação: Abordagens Qualitativas. 2a ed. Rio de Janeiro: LTC, 2013.

MIT - Massachussets Institute of Technology. 2012. App Inventor for Android. Disponível em: 
<http://appinventor.mit.edu/about-us> Acesso em: 20 de abril de 2019.

SAELI, M. J. , PERREneti, W. M.G., JOCHEMS, B. Z. A Pedagogical Content Knowledge in programming education for secondary school: Perspective. In ICER'11 proceedings of the 7th international workshop on Computing Education Research. Volume 10 (1): 145- 146, 2011.

PARCIANELLO, L; KONZEN, P.C. 2016. Docência no ensino superior: o uso das novas tecnologias na formação de professores na licenciatura. Disponível em:

<http://www.arcos.org.br/artigos/docencia-no-ensino-superior-o-uso-das-novas- tecnologias-na-formacao-deprofessores-na-licenciatura/\#topo> Acessado em: 05 de fevereiro de 2019.

ROCHA, P. S.; FERREIRA, B., MONTEIRO, D.; NUNES, D.S. C.; GOÉS, H. C. N. Ensino e Aprendizagem de Programação: Análise da Aplicação de Proposta Metodológica Baseada no Sistema Personalizado de Ensino. Renote - Revista Novas Tecnologias na Educação, Porto Alegre - RS, Brasil. v. 8, n. 3, 2010.

SCAICO, P. D.; LIMA, A.A.; SILVA, J. B. B.; AZEVEDO, S. ; PAIVA, L. F.; RAPOSO, E. H.; ALENCAR, Y.; MENDES, J. P.; SCAICO, A. Ensino de Programação no Ensino Médio: Uma Abordagem Orientada ao Design com a linguagem Scratch. Revista Brasileira de Informática na Educação, Volume 21, 2013. 